\title{
Long-term hospital admissions and surgical treatment of children with congenital abdominal wall defects: a population-based study
}

\author{
Arimatias Raitio $^{1}$ (D) Johanna Syvänen ${ }^{1} \cdot$ Asta Tauriainen $^{1,2} \cdot$ Anna Hyvärinen $^{3}$ • Ulla Sankilampi ${ }^{4} \cdot$ Mika Gissler $^{5,6}$. \\ Ilkka Helenius ${ }^{7}$
}

Received: 21 January 2021 / Revised: 23 February 2021 / Accepted: 25 February 2021 / Published online: 5 March 2021

(C) The Author(s) 2021

\begin{abstract}
Congenital abdominal wall defects, namely, gastroschisis and omphalocele, are rare congenital malformations with significant morbidity. The long-term burden of these anomalies to families and health care providers has not previously been assessed. We aimed to determine the need for hospital admissions and the requirement for surgery after initial admission at birth. For our analyses, we identified all infants with either gastroschisis $(n=178)$ or omphalocele $(n=150)$ born between Jan 1, 1998, and Dec 31, 2014, in the Register of Congenital Malformations. The data on all hospital admissions and operations performed were acquired from the Finnish Hospital Discharge Register between Jan 1, 1998, and Dec 31, 2015, and compared to data on the whole Finnish pediatric population (0.9 million) live born 1993-2008. Patients with gastroschisis and particularly those with omphalocele required hospital admissions 1.8 to 5.7 times more than the general pediatric population $(p<0.0001)$. Surgical interventions were more common among omphalocele than gastroschisis patients $(p=0.013)$. At the mean follow-up of 8.9 (range $1.0-18.0)$ years, $29 \%(51 / 178)$ of gastroschisis and 30\% (45/150) of omphalocele patients required further abdominal surgery after discharge from the neonatal admission.

Conclusion: Patients with gastroschisis and especially those with omphalocele, are significantly more likely than the general pediatric population to require hospital care. Nevertheless, almost half of the patients can be treated without further surgery, and redo abdominal surgery is only required in a third of these children.
\end{abstract}

What is Known:

- Gastroschisis and omphalocele are congenital malformations with significant morbidity

- There are no reports on the long-term need for hospital admissions and surgery in these children

What is New:

- Patients with abdominal wall defects are significantly more likely than the general pediatric population to require hospital care

- Almost half of the patients can be treated without further surgery, and abdominal redo operations are only required in a third of these children

Keywords Congenital abdominal wall defect $\cdot$ Exomphalos $\cdot$ Gastroschisis $\cdot$ Omphalocele $\cdot$ Hospital care

Communicated by Piet Leroy

Arimatias Raitio

arimatias.raitio@fimnet.fi

Johanna Syvänen

johanna.syvanen@fimnet.fi

Asta Tauriainen

asta.tauriainen@fimnet.fi

Anna Hyvärinen

anna.hyvarinen@tuni.fi

\author{
Ulla Sankilampi \\ ulla.sankilampi@kuh.fi \\ Mika Gissler \\ mika.gissler@thl.fi \\ Ilkka Helenius \\ ilkka.helenius@helsinki.fi
}

Extended author information available on the last page of the article 


\section{Introduction}

Major congenital anomalies, including gastroschisis and omphalocele, have an impact on the quality and length of life of affected individuals. Both these aforementioned abdominal wall defects (AWDs) are relatively rare congenital anomalies with respective prevalences of 1.85 and 1.96 per 10,000 births in Finland [1, 2]. Gastroschisis often presents as an isolated anomaly $[1,3]$ and has good long-term outcomes, and abdominal reoperations are rarely required [4]. Omphalocele, on the other hand, is often associated with other severe comorbidities including chromosomal abnormalities and cardiac defects $[2$, $5,6]$. Consequently, up to $60 \%$ of patients with giant omphalocele suffer from persistent medical problems [7, 8]. However, long-term complaints are rare among patients with small omphalocele [9].

There are a handful of studies on the burden imposed by selected congenital anomalies and Down's syndrome on hospital care [10-14]. The data on the need, duration, and frequency of hospital admissions and surgical treatment are important not only for health care providers but also for families and caregivers preparing to live with a child with a congenital anomaly. Early studies have demonstrated that gastroschisis is associated with significant morbidity and even mortality after the neonatal period [15], especially among patients with complex gastroschisis [16-18]. However, there are so far no published studies on the long-term need for hospital admission and operations among patients with gastroschisis and particularly omphalocele during childhood.

The purpose of this population-based register study was therefore to assess the burden associated with AWDs on patients' families and on the health care system by determining the number of hospital admissions, total time spent in hospital, and the number of surgical interventions in children with gastroschisis and omphalocele. Additionally, we wanted to compare these data with those of the general pediatric population of our country. We hypothesized that children with gastroschisis would have significantly less need for hospital readmissions and redo abdominal surgery after initial admission than children with omphalocele.

\section{Material and methods}

All children born with AWD between Jan 1, 1998, and Dec 31, 2014, were identified in the Finnish Register of Congenital Malformations (FRM) allowing a minimum of one-year follow-up. The register contains data on all live births, stillbirths, and fetuses from spontaneous abortions and elective terminations of pregnancy for fetal anomalies, all with at least one major congenital anomaly. These anomalies and chromosomal defects are coded according to an extended version of the 9th Revision of the International
Classification of Diseases (ICD-9) of the World Health Organization. According to the system of the European Surveillance of Congenital Anomalies (EUROCAT) [19], minor anomalies were excluded. The data on hospital admissions were collected from the Finnish Hospital Discharge Register (FHDR). Both these registers are maintained by the Finnish Institute for Health and Welfare (THL).

FRM receives nationwide data on congenital and fetal anomalies from hospitals, healthcare professionals, and cytogenic laboratories. With the help of the unique personal identification code (PIC), FRM also draws data from other national health registers including Medical Birth Register, Register on Induced Abortions, FHDR, and The Register of Visual Impairment, all maintained by THL, as well as from Cause-of-Death Register, maintained by Statistics Finland. The data quality and coverage of these registers have been validated and considered good in several studies [20-23].

Nationwide data on all hospital discharges and outpatient visits are registered in FHDR, and the study population identified in FRM was cross-linked with the FHDR data by the PIC. Basic variables collected in FHDR include the date of birth, sex, area of residence, admission and discharge dates, surgical procedures, and diagnoses of patients' medical problems. Diagnoses were recorded according to the ICD-10, and the operations were registered according to the Finnish version of NOMESCO (Nordic Medico-Statistical Committee) Classification of Surgical Procedures (NCSP). Numbers of all hospital admissions in gastroschisis and omphalocele patients (excluding the birth episode) between Jan 1, 1998, and Dec 31, 2015, were analyzed and compared with the whole live born pediatric population 1993-2008 $(n=942,692)$. Surgical and nonsurgical admissions were analyzed separately including days spent in the hospital, as well as number and type of surgical operations. Surgical procedures were categorized by surgical specialty and general pediatric surgery procedures by anatomical location (abdominal, groin, and intravenous access).

\section{Statistical analysis}

A one-sample $t$ test was used to compare continuous variables, and Kaplan-Meier analysis was utilized for operation-free survival. A significance level of $p<0.05$ (two-tailed) was set. Analyses were performed using JMP Pro, version 13.1.0 for Windows (SAS Institute Inc., Cary, North Carolina, USA).

\section{Ethical considerations}

The approval of the Institutional Review Board at Turku University Hospital was obtained before conducting this study. The Finnish Institute for Health and Welfare gave permission to use their health register data in this study. 


\section{Results}

We identified 178 infants with gastroschisis and 150 with omphalocele in the registers born between Jan 1, 1998, and Dec 31, 2014. These 328 children with AWDs had altogether 1,507 hospital admissions and spent 7,465 days in the hospital during our 18-year study period (Table 1). The median followup time was 8.2 (range 1.0-18.0) years for gastroschisis and 9.9 (range 1.2-17.9) years for omphalocele patients. The whole live born pediatric population 1993-2008, used as a reference, had 1,524,481 hospital admissions in total with 4,194,675 hospital days during the 17-year period. The mean number of hospital admissions in our control population was thus 0.10 , and the mean length of inpatient care is 0.3 days per child per year.

In gastroschisis patients, the annual mean number of hospital admissions was 0.18 with 0.9 days on average spent in the hospital. The corresponding numbers for omphalocele were 0.34 admissions and 1.7 days in hospital annually. In gastroschisis patients, the number of admissions and inpatient days was, respectively, 1.8 and 3.0 times higher than that in the general population $(p<0.0001$ and $p=0.003)$. Omphalocele patients, on the other hand, were annually 3.4 times more likely to be admitted to the hospital and spent 5.7-fold more days per year as inpatients ( $p<0.0001$ for both). The majority of the admissions were nonsurgical among both gastroschisis and omphalocele patients; $71 \%$ and $64 \%$ of all admissions, respectively. The first year of life accounted for $45 \%$ of these admissions in gastroschisis and 35\% in omphalocele patients.

The most common types of surgery were ear, nose, and throat (ENT) operations, gastrointestinal (GI) surgery, and groin surgery, which included operations for inguinal hernia and undescended testicles. Bowel obstruction required surgery in nine $(5 \%)$ gastroschisis and four (3\%) omphalocele patients. Other laparotomies in 20 gastroschisis and 18 omphalocele patients involved bowel resections, stoma formations and closures, and antireflux surgery. A significant number of operations related to intravenous (IV) access were observed among patients with omphalocele, and contrary to the gastroschisis cohort, they also required cardiac and urological procedures (Table 2).

Patients with omphalocele were statistically more likely to require surgery than those with gastroschisis after their initial admission ( $p=0.013$, Fig. 1). Gastrointestinal operations and/ or abdominal wall hernia operations were equally common in both patient groups: 51/178 (29\%) in gastroschisis and 45/150 (30\%) in omphalocele (Fig. 2). Recurrent or residual abdominal wall hernia operations were performed in 25/178 (14\%) patients with gastroschisis and 28/150 (19\%) with omphalocele. As presented in Fig. 1, the majority of omphalocele patients (55\%) and $48 \%$ of gastroschisis patients requiring surgery were operated on before the age of one year, and after, infancy surgical intervention was required less often.

\section{Discussion}

According to this population-based study, the need for hospital care among patients with AWDs is multiple-fold compared to the general pediatric population. To the best of our knowledge, no studies on long-term need for care and operations among AWD patients have been published. Children with major birth defects have been reported to be 2.5 times more likely on average to require hospital care than children without congenital defects [10], and even higher numbers have been reported with orofacial clefts [13] and limb deficiencies [14].

In our study, both gastroschisis and omphalocele were associated with significantly higher frequency and duration of hospital admissions than the general pediatric population. An Australian study by Colvin et al. [10] reported childhood hospital admissions to be 2.5 times more likely among children with major congenital anomalies, which is well within the range of our findings among gastroschisis patients. Omphalocele, on the other hand, was associated with over fivefold risk of inpatient stay, which is comparable with English national hospital admission data on patients with cleft lip and/or palate [13]. We postulate that the greater number of hospital admissions in omphalocele is likely a reflection of the greater number of associated anomalies and syndromes often seen in these patients $[2,24-26]$.

Less than half of the patients with gastroschisis (48\%) required surgical intervention after their initial admission at birth. According to the published literature, umbilical hernia appears to be rather common after gastroschisis repair [27, 28]. Sutureless closure has been reported to be associated with
Table 1 The number of patients with hospital admissions in gastroschisis and omphalocele

\begin{tabular}{lll}
\hline & $\begin{array}{l}\text { Patients with hospital admissions }(\%) \\
\text { Range of admissions/patient }\end{array}$ & $\begin{array}{l}\text { Median days in hospital } \\
\text { (range) }\end{array}$ \\
\hline Gastroschisis $(n=178)$ & $143(80.3 \%)$ & 5 \\
Omphalocele $(n=150)$ & $0-31$ & $(0-302)$ \\
& $116(77.3 \%)$ & 6 \\
& $0-63$ & $(0-387)$ \\
\hline
\end{tabular}


Table 2 The percentage and number of patients requiring surgery after initial admission among gastroschisis and omphalocele patients

\begin{tabular}{|c|c|c|c|c|c|c|c|c|}
\hline & $\begin{array}{l}\text { All surgery } \\
(n) \\
\text { Range of } \\
\text { operations/ } \\
\text { patient }\end{array}$ & $\begin{array}{l}\text { GI surgery } \\
\text { (n) } \\
\text { Range } \\
\text { of operations/ } \\
\text { patient }\end{array}$ & $\begin{array}{l}\text { Groin surgery } \\
(n) \\
\text { Range } \\
\text { of operations/ } \\
\text { patient }\end{array}$ & $\begin{array}{l}\text { IV access } \\
(n) \\
\text { Range } \\
\text { of operations/ } \\
\text { patient }\end{array}$ & $\begin{array}{l}\text { Urologic } \\
\text { surgery } \\
(n) \\
\text { Range } \\
\text { of operations/ } \\
\text { patient }\end{array}$ & $\begin{array}{l}\text { Orthopedic } \\
\text { surgery } \\
(n) \\
\text { Range } \\
\text { of operations/ } \\
\text { patient }\end{array}$ & $\begin{array}{l}\text { ENT } \\
\text { operations } \\
(n) \\
\text { Range } \\
\text { of operations/ } \\
\text { patient }\end{array}$ & $\begin{array}{l}\text { Cardiac } \\
\text { surgery } \\
(n) \\
\text { Range } \\
\text { of operations/ } \\
\text { patient }\end{array}$ \\
\hline $\begin{array}{c}\text { Gastroschisis } \\
\quad(n=178)\end{array}$ & $\begin{array}{l}48 \%(86) \\
0-14\end{array}$ & $\begin{array}{l}16 \%(29) \\
0-4\end{array}$ & $\begin{array}{l}14 \%(25) \\
0-2\end{array}$ & $\begin{array}{l}8 \%(15) \\
0-4\end{array}$ & 0 & $\begin{array}{l}2 \%(4) \\
0-2\end{array}$ & $\begin{array}{l}19 \%(33) \\
0-7\end{array}$ & 0 \\
\hline $\begin{array}{l}\text { Omphalocele } \\
(n=150)\end{array}$ & $\begin{array}{l}62 \%(93) \\
0-31\end{array}$ & $\begin{array}{l}15 \%(22) \\
0-6\end{array}$ & $\begin{array}{l}25 \%(37) \\
0-4\end{array}$ & $\begin{array}{l}15 \%(23) \\
0-3\end{array}$ & $\begin{array}{l}6 \%(9) \\
0-15\end{array}$ & $\begin{array}{l}7 \%(11) \\
0-12\end{array}$ & $\begin{array}{l}23 \%(34) \\
0-9\end{array}$ & $\begin{array}{l}8 \%(12) \\
0-6\end{array}$ \\
\hline
\end{tabular}

$13 \%$ incidence of umbilical hernia requiring surgical repair [28]. We reported a surgical repair rate of $14 \%$, which may at least partially be explained by the longer follow-up period than in previously published studies. De Bie et al. reported a $5.6 \%$ risk of acute abdominal complications in long-term follow-up among patients with simple gastroschisis. In our cohort, $17 \%$ of patients underwent GI surgical operations including both elective and emergency procedures. However, our cohort also included patients with complex gastroschisis which is reported to be associated with over $60 \%$ risk of reoperation [29].

Majority of omphalocele patients $(62 \%)$ required surgical care after being discharged. As omphalocele is often associated with other congenital anomalies, a wider range of operations including cardiac, orthopedic, and urological surgery was performed on omphalocele patients in contrast to gastroschisis. Also, operations for undescended testicles were more common among omphalocele than among gastroschisis patients as we reported earlier [30]. Adhesive bowel obstruction has previously been reported to occur in up to $15 \%$ of omphalocele patients $[31,32]$, which is in line with our $15 \%$ frequency of GI surgical reoperation reported here. The requirement for reoperation(s) due to abdominal wall defect depends on the size of the defect and the methods of treatment [33]. We reported a somewhat

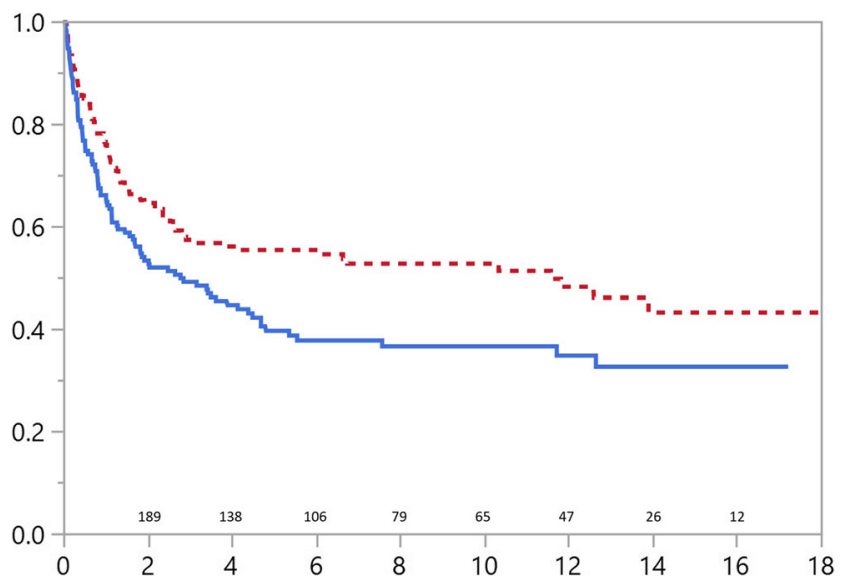

Fig. 1 Operation-free survival for patients with abdominal wall defects. Solid line representing omphalocele and dotted line gastroschisis patients. Number of patients at risk and years of follow-up in $x$ scale higher rate of hernia operations among omphalocele patients than in gastroschisis (19\% vs. 14\%). However, this is likely to include cases with initial conservative treatment of the defect with delayed fascial closure, which makes comparison with previous data challenging.

The strength of the study is that the register data stored in the FRM and the FHDR are both validated with high accuracy and full country coverage $[34,35]$. All hospitals report to the register, and there are no private children's hospitals in Finland. Before entering the data in the register, all case data were further validated by examining all available medical records and radiographs. Furthermore, hospitals are expected to report the diagnosis and operation codes accurately as these are the bases for hospital billing [36]. In addition, the data on the control group was derived from a population-based register. The weakness of this study is the shorter follow-up time in cases born recently.

In conclusion, patients with congenital AWD, especially those with omphalocele, are significantly more likely to require hospital care than the general pediatric population. However, almost half of the patients can be treated without further surgery, and redo abdominal surgery is only required in a third of these children.

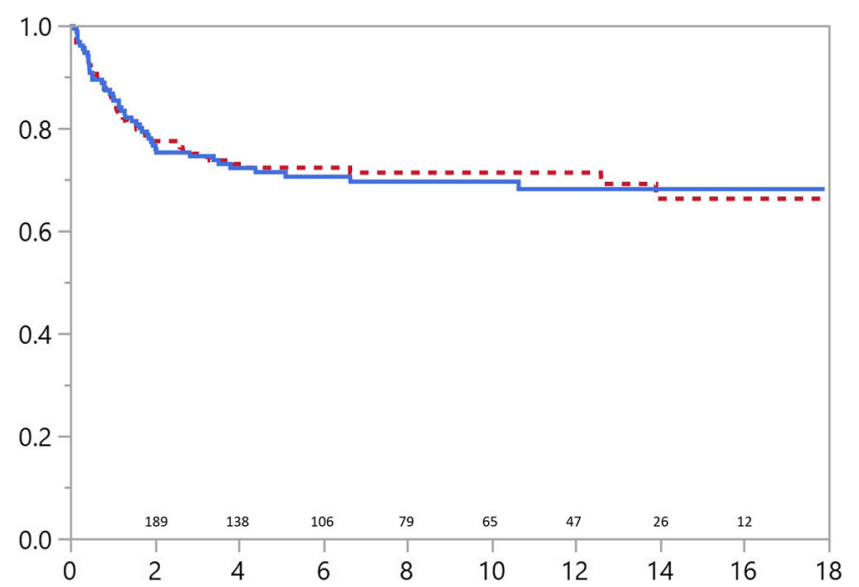

Fig. 2. Survival without redo abdominal or abdominal wall hernia surgery in patients with abdominal wall defects. Solid line depicting omphalocele and dotted line gastroschisis patients 
Abbreviations $A W D$, Abdominal wall defect; $E N T$, Ear, nose, and throat; FHDR, Finnish Hospital Discharge Register; FRM, Finnish Register of Congenital Malformations; GI, Gastrointestinal; ICD, International Classification of Diseases; $I V$, Intravenous; PIC, Personal identification code; $T H L$, Finnish Institute for Health and Welfare

Authors' contributions All authors contributed to the study conception and design. Material preparation, data collection, and analysis were performed by AR, MG, JS, and IH. The first draft of the manuscript was written by AR, and all authors commented on previous versions of the manuscript. All authors have read and approved the final manuscript.

Funding Open access funding provided by University of Turku (UTU) including Turku University Central Hospital. Dr. Raitio, Dr. Helenius, and Dr. Syvänen report grants from the Clinical Research Institute $\mathrm{HUCH}$, and Dr. Raitio reports grants from the Emil Aaltonen Foundation and Finnish Pediatric Research Foundation.

Data Availability The data that support the findings of this study are available from the corresponding author upon reasonable request.

Code availability JMP Pro, version 13.1 .0 for Windows (SAS Institute Inc., Cary, North Carolina, USA).

\section{Declarations}

Ethical approval This article does not contain any studies with human participants or animals performed by any of the authors. The Institute for Health and Welfare and Institutional Review board at Turku University Hospital approved this national register-based study.

\section{Consent to participate Not applicable}

\section{Consent for publication Not applicable}

Conflict of interest The authors report no conflicts of interest related to the current study. IH has received funding from the Industry outside this study (Medtronic, Stryker).

Open Access This article is licensed under a Creative Commons Attribution 4.0 International License, which permits use, sharing, adaptation, distribution and reproduction in any medium or format, as long as you give appropriate credit to the original author(s) and the source, provide a link to the Creative Commons licence, and indicate if changes were made. The images or other third party material in this article are included in the article's Creative Commons licence, unless indicated otherwise in a credit line to the material. If material is not included in the article's Creative Commons licence and your intended use is not permitted by statutory regulation or exceeds the permitted use, you will need to obtain permission directly from the copyright holder. To view a copy of this licence, visit http://creativecommons.org/licenses/by/4.0/.

\section{References}

1. Raitio A, Lahtinen A, Syvänen J, Kemppainen T, Löyttyniemi E, Gissler M, Hyvärinen A, Helenius I (2020) Gastroschisis in Finland 1993 to 2014-increasing prevalence, high rates of abortion, and survival: a population-based study. Eur J Pediatr Surg 30:536540. https://doi.org/10.1055/s-0039-3401797
2. Raitio A, Tauriainen A, Syvänen J, Kemppainen T, Löyttyniemi E, Sankilampi U, Vanamo K, Gissler M, Hyvärinen A, Helenius I (2020) Omphalocele in Finland from 1993 to 2014: trends, prevalence, mortality, and associated malformations-a population-based study. Eur J Pediatr Surg 2020. https://doi.org/10.1055/s-00401703012

3. Anderson JE, Galganski LA, Cheng Y, Stark RA, Saadai P, Stephenson JT, Hirose S (2018) Epidemiology of gastroschisis: a population-based study in California from 1995 to 2012. J Pediatr Surg 53:2399-2403

4. De Bie F, Swaminathan V, Johnson G, Monos S, Adzick NS, Laje P (2020) Long-term core outcomes of patients with simple gastroschisis. J Pediatr Surg. https://doi.org/10.1016/j.jpedsurg. 2020.09.008

5. Yazbeck S, Ndoye M, Khan AH (1986) Omphalocele: a 25-year experience. J Pediatr Surg 21:761-763. https://doi.org/10.1016/ s0022-3468(86)80360-8

6. Stoll C, Alembik Y, Dott B, Roth MP (2001) Risk factors in congenital abdominal wall defects (omphalocele and gastroschisi): a study in a series of 265,858 consecutive births. Ann Genet 44: 201-208. https://doi.org/10.1016/s0003-3995(01)01094-2

7. Koivusalo A, Rintala R, Lindahl H (1999) Gastroesophageal reflux in children with a congenital abdominal wall defect. J Pediatr Surg 34:1127-1129. https://doi.org/10.1016/s0022-3468(99)90582-1

8. Biard JM, Wilson RD, Johnson MP, Hedrick HL, Schwarz U, Flake AW, Crombleholme TM, Adzick NS (2004) Prenatally diagnosed giant omphaloceles: short- and long-term outcomes. Prenat Diagn 24:434-439. https://doi.org/10.1002/pd.894

9. Christison-Lagay ER, Kelleher CM, Langer JC (2011) Neonatal abdominal wall defects. Semin Fetal Neonatal Med 16:164-172. https://doi.org/10.1016/j.siny.2011.02.003

10. Colvin L, Bower C (2009) A retrospective population-based study of childhood hospital admissions with record linkage to a birth defects registry. BMC Pediatr 9:32. https://doi.org/10.1186/14712431-9-32

11. Billett J, Majeed A, Gatzoulis M, Cowie M (2008) Trends in hospital admissions, in-hospital case fatality and population mortality from congenital heart disease in England, 1994 to 2004. Heart 94: 342-348. https://doi.org/10.1136/hrt.2006.113787

12. Fitzgerald P, Leonard H, Pikora TJ, Bourke J, Hammond G (2013) Hospital admissions in children with down syndrome: experience of a population-based cohort followed from birth. PLoS One 8: e70401. https://doi.org/10.1371/journal.pone.0070401

13. Fitzsimons KJ, Copley LP, Deacon SA, van der Meulen JH (2013) Hospital care of children with a cleft in England. Arch Dis Child 98: 970-974. https://doi.org/10.1136/archdischild-2013-304271

14. Syvänen J, Helenius I, Koskimies-Virta E, Ritvanen A, Hurme S, Nietosvaara Y (2019) Hospital admissions and surgical treatment of children with lower-limb deficiency in Finland. Scand J Surg 108: 352-360. https://doi.org/10.1177/1457496918812233

15. van Manen M, Hendson L, Wiley M, Evans M, Taghaddos S, Dinu I (2013) Early childhood outcomes of infants born with gastroschisis. J Pediatr Surg 48:1682-1687. https://doi.org/10. 1016/j.jpedsurg.2013.01.021

16. Harris EL, Minutillo C, Hart S, Warner TM, Ravikumara M, Nathan EA, Dickinson JE (2014) The long term physical consequences of gastroschisis. J Pediatr Surg 49:1466-1470. https://doi. org/10.1016/j.jpedsurg.2014.03.008

17. Risby K, Husby S, Qvist N, Jakobsen MS (2017) High mortality among children with gastroschisis after the neonatal period: a longterm follow-up study. J Pediatr Surg 52:431-436. https://doi.org/ 10.1016/j.jpedsurg.2016.08.022

18. Lap CC, Brizot ML, Pistorius LR, Kramer WL, Teeuwen IB, Eijkemans MJ, Brouwers HA, Pajkrt E, van Kaam AH, van Scheltema PN, Eggink AJ, van Heijst AF, Haak MC, van Weissenbruch MM, Sleeboom C, Willekes C, van der Hoeven 
MA, van Heurn EL, Bilardo CM, Dijk PH, van Baren R, Francisco RP, Tannuri AC, Visser GH, Manten GT (2016) Outcome of isolated gastroschisis; an international study, systematic review and meta-analysis. Early Hum Dev 103:209-218. https://doi.org/10. 1016/j.earlhumdev.2016.10.002

19. EUROCAT European Surveillance of Congenital Anomalies. www.eurocat-network.eu. Accessed 7 Jan 2021

20. Pakkasjärvi N, Ritvanen A, Herva R, Peltonen L, Kestilä M, Ignatius J (2006) Lethal congenital contracture syndrome (LCCS) and other lethal arthrogryposes in Finland-an epidemiological study. Am J Med Genet A 140A:1834-1839. https://doi.org/10. 1002/ajmg.a.31381

21. Leoncini E, Botto LD, Cocchi G, Anneren G, Bower C, Halliday J, Amar E et al (2010) How valid are the rates of Down syndrome internationally? Findings from the International Clearinghouse for Birth Defects Surveillance and Research. Am J Med Genet A 152A: 1670-1680. https://doi.org/10.1002/ajmg.a.33493

22. Gissler M, Teperi J, Hemminki E, Merilainen J (1995) Data quality after restructuring a national medical registry. Scand J Soc Med 23: 75-80. https://doi.org/10.1177/140349489502300113

23. Greenlees R, Neville A, Addor MC, Amar E, Arriola L, Bakker M, Barisic I, Boyd PA, Calzolari E, Doray B, Draper E, Emil Vollset S, Garne E, Gatt M, Haeusler M, Kallen K, Khoshnood B, LatosBielenska A, Martinez-Frias ML, Materna-Kiryluk A, Matias Dias C, McDonnell B, Mullaney C, Nelen V, O'Mahony M, Pierini A, Queisser-Luft A, Randrianaivo-Ranjatoélina H, Rankin J, Rissmann A, Ritvanen A, Salvador J, Sipek A, Tucker D, Verellen-Dumoulin C, Wellesley D, Wertelecki W (2011) Paper 6: EUROCAT member registries: organization and activities. Birth Defects Res A Clin Mol Teratol 91(Suppl 1):S51-S100. https://doi.org/10.1002/bdra.20775

24. Stoll C, Alembik Y, Dott B, Roth MP (2008) Omphalocele and gastroschisis and associated malformations. Am J Med Genet A 146A:1280-1285. https://doi.org/10.1002/ajmg.a.32297

25. Deng K, Qiu J, Dai L, Yi L, Deng C, Mu Y, Zhu J (2014) Perinatal mortality in pregnancies with omphalocele: data from the Chinese national birth defects monitoring network, 1996-2006. BMC Pediatr 14:160. https://doi.org/10.1186/1471-2431-14-160

26. Byron-Scott R, Haan E, Chan A, Bower C, Scott H, Clark K (1998) A population-based study of abdominal wall defects in South Australia and Western Australia. Paediatr Perinat Epidemiol 12: 136-151. https://doi.org/10.1046/j.1365-3016.1998.00090.x

27. Tullie LG, Bough GM, Shalaby A, Kiely EM, Curry JI, Pierro A, De Coppi P, Cross KM (2016) Umbilical hernia following gastroschisis closure: a common event? Pediatr Surg Int 32:811814. https://doi.org/10.1007/s00383-016-3906-1

28. Witt RG, Zobel M, Padilla B, Lee H, MacKenzie TC, Vu L (2019) Evaluation of clinical outcomes of sutureless vs sutured closure techniques in gastroschisis repair. JAMA Surg 154:33-39. https:// doi.org/10.1001/jamasurg.2018.3216

29. Carpenter JL, Wiebe TL, Cass DL, Olutoye OO, Lee TC (2016) Assessing quality of life in pediatric gastroschisis patients using the Pediatric Quality of Life Inventory survey: an institutional study. J Pediatr Surg 51:726-729. https://doi.org/10.1016/j.jpedsurg.2016. 02.012

30. Raitio A, Syvänen J, Tauriainen A, Hyvärinen A, Sankilampi U, Gissler M, Helenius I (2021) Congenital abdominal wall defects and cryptorchidism: a population-based study. Pediatr Surg Int 2021. https://doi.org/10.1007/s00383-021-04863-9

31. Tunell WP, Puffinbarger NK, Tuggle DW, Taylor DV, Mantor PC (1995) Abdominal wall defects in infants. Survival and implications for adult life. Ann Surg 221:525-528; discussion 528-530. https:// doi.org/10.1097/00000658-199505000-00010

32. van Eijck FC, Wijnen RM, van Goor H (2008) The incidence and morbidity of adhesions after treatment of neonates with gastroschisis and omphalocele: a 30-year review. J Pediatr Surg 43:479-483. https://doi.org/10.1016/j.jpedsurg.2007.10.027

33. Bauman B, Stephens D, Gershone H, Bongiorno C, Osterholm E, Acton R, Hess D, Saltzman D, Segura B (2016) Management of giant omphaloceles: a systematic review of methods of staged surgical vs. nonoperative delayed closure. J Pediatr Surg 51:17251730. https://doi.org/10.1016/j.jpedsurg.2016.07.006

34. THL Register of Congenital Malformations. Finnish Institute for Health and Welfare. https://thl.fi/en/web/thlfi-en/statistics/ information-on-statistics/register-descriptions/register-ofcongenital-malformations. Accessed 2020, Nov 10.

35. Sund R (2012) Quality of the Finnish Hospital Discharge Register: a systematic review. Scand J Public Health 40:505-515. https://doi. org/10.1177/1403494812456637

36. THL Care Register for Health Care. https://thl.fi/en/web/thlfi-en/ statistics/information-on-statistics/register-descriptions/careregister-for-health-care. Accessed 2020, Nov 30.

Publisher's note Springer Nature remains neutral with regard to jurisdictional claims in published maps and institutional affiliations.

\section{Affiliations}

\section{Arimatias Raitio $^{1}$ (D) - Johanna Syvänen ${ }^{1}$ • Asta Tauriainen ${ }^{1,2}$ • Anna Hyvärinen ${ }^{3}$ • Ulla Sankilampi ${ }^{4}$ Mika Gissler $^{5,6}$. Ilkka Helenius ${ }^{7}$}

1 Department of Paediatric Surgery, University of Turku and Turku University Hospital, Kiinamyllynkatu 4-8, 20521 Turku, Finland

2 University of Eastern Finland, Kuopio, Finland

3 Department of Paediatric Surgery, University of Tampere and Tampere University Hospital, Tampere, Finland

4 Department of Paediatrics, Kuopio University Hospital, Kuopio, Finland
5 Information Services Department, Finnish Institute for Health and Welfare, Helsinki, Finland

6 Department of Neurobiology, Care Sciences and Society, Karolinska Institute, Solna, Sweden

7 Department of Orthopaedics and Traumatology, University of Helsinki and Helsinki University Hospital, Helsinki, Finland 